\title{
Recent Advances in Carbon Capture with Metal-Organic Frameworks
}

\author{
Kyriakos C. Stylianou* and Wendy L. Queen*
}

\begin{abstract}
The escalating level of $\mathrm{CO}_{2}$ in the atmosphere is one of the most critical environmental issues of our age. The carbon capture and storage from pilot test plants represents an option for reducing $\mathrm{CO}_{2}$ emissions, however, the energy cost associated with post-combustion carbon capture process alone is $\sim 30 \%$ of the total energy generated by the power plant. Thus, the generation of carbon capture adsorbents with high uptake capacities, great separation performance and low cost is of paramount importance. Metal-organic frameworks are infinite networks of metal-containing nodes bridged by organic ligands through coordination bonds into porous extended structures and several reports have revealed that they are ideal candidates for the selective capture of $\mathrm{CO}_{2}$. In this review we summarize recent advances related to the synthesis of porous MOFs and the latest strategies to enhance the $\mathrm{CO}_{2}$ adsorption enthalpies and capacities at low-pressures, increase hydrolytic and mechanical stabilities, and improve the ease of regeneration. Although they show great promise for postcombustion carbon capture, there are still major challenges that must be overcome before they can be used for such a large-scale application.
\end{abstract}

Keywords: $\mathrm{CO}_{2}$ capture - Flue gas · Hydrolytic stability and regeneration · Metal-organic frameworks (MOF) MOF synthesis $\cdot$ Selectivity

\section{Introduction}

Research towards carbon capture and sequestration technologies (CCS) attracts much attention at present due to alarming reports that reveal a positive correlation between global warming and atmospheric $\mathrm{CO}_{2}$ levels. ${ }^{[1]}$ These levels have progressively increased since the 1970 s by a factor of $30 \%$ due to population growth and continued industrialization of developing countries. ${ }^{[2]}$ Carbon dioxide emissions are principally produced from the combustion of fossil fuels, which supply $80 \%$ of global energy. ${ }^{[2,3]}$ The largest percentage of these emissions results from power plants and passenger vehicles, with the global output being 20 billion tons per year (Fig. 1a). ${ }^{[4]}$ Thus, there is a critical need to reduce $\mathrm{CO}_{2}$ emissions and trend back toward pre-industrial atmospheric conditions, a process that will require multipronged advances across science, technology, and industry and significant changes in human behavior. Given that energy transitions are his-

$\overline{{ }^{*} \text { Correspondence: }}$ Dr. K. C. Stylianou,

Prof. W. L. Queen

École Polytechnique Fédérale de Lausanne (EPFL) Institute of Chemical Sciences and Engineering EPFL-ISIC-Valais, Sion

E-mail: kyriakos.stylianou@epfl.ch and wlqueen@lbl.gov torically slow, relatively long timescales are anticipated for the development of affordable and environmentally friendly large-scale renewable energy sources (solar, wind, geothermal, bioenergy, etc.). ${ }^{[5]}$ In addition to this, the rapidly increasing global energy demand, and the continued availability of various carbon-based fuels (in particular coal and gas), fossil fuel use is projected to continue to increase over the coming decades. As such, there is an urgent need to expedite the development of carbon capture technologies that can limit the amount of $\mathrm{CO}_{2}$ released into the atmosphere.

While carbon capture from air is a difficult task, CCS is a viable way to limit future $\mathrm{CO}_{2}$ emissions from large, stationary sources such as coal-fired power plants. Post-combustion carbon capture first requires the selective capture/extraction of $\mathrm{CO}_{2}$ from the flue gas $\left(\sim 70-75 \% \mathrm{~N}_{2}\right.$, $\sim 15-16 \% \mathrm{CO}_{2}, \sim 5-7 \% \mathrm{H}_{2} \mathrm{O}$ and $\sim 3-4 \%$ $\mathrm{O}_{2}$ with other minor contaminants), followed by its compression, transportation and subsequent storage underground.[4b] The initial capture/extraction process is particularly challenging due to the low concentration of $\mathrm{CO}_{2}$ in the flue gas stream and the similarities in size and shape of the two major components, $\mathrm{N}_{2}$ and $\mathrm{CO}_{2}$, allowing limited scope for their differentiation from a materials perspective. While some important differences exist between $\mathrm{CO}_{2}$ and $\mathrm{N}_{2}$, notably in both the strength of their intermolecular interactions and chemical reactivity, these differences necessitate the design of carbon capture materials that exhibit strong, molecule specific chemical interactions. ${ }^{[6]}$

From all of the available technologies for post-combustion $\mathrm{CO}_{2}$ capture (membranes, cryogenic distillation, absorption, and adsorption), ${ }^{[3 a, 7]}$ the most mature technology involves aqueous amine-based scrubbers that selectively react with the $\mathrm{CO}_{2} \cdot{ }^{[8]}$ Implementation of these methodologies on a large scale however is limited by their corrosive nature and large regeneration energies, a direct result of strong $\mathrm{CO}_{2}$ binding and high heat capacities. These problems lead to a range of technological difficulties with the largest impediment related to a high parasitic energy loss. At present, the energy cost associated with the post-combustion carbon capture process alone is $\sim 30 \%$ of the total energy generated by the power plant.[6b] It is projected that adsorption-based capture technologies, which involve the selective adsorption of $\mathrm{CO}_{2}$ from flue gas through favorable intermolecular forces between $\mathrm{CO}_{2}$ molecules and a solid porous adsorbent, could reduce this parasitic loss by over 50\%. Adsorption-based techniques are promising due to their inherent simplicity, low operational requirements, ease of control and high efficiency. To date, several porous materials such as zeolites, molecular cages, activated carbons and covalent organic frameworks (COFs) have been systematically studied for the capture of $\mathrm{CO}_{2}$ - however they show some limitations. ${ }^{[9]}$ Zeolites, for example, typically show rapid selective adsorption of $\mathrm{CO}_{2}$ but low $\mathrm{CO}_{2}$ adsorption capacity, ${ }^{[10]}$ while po- 


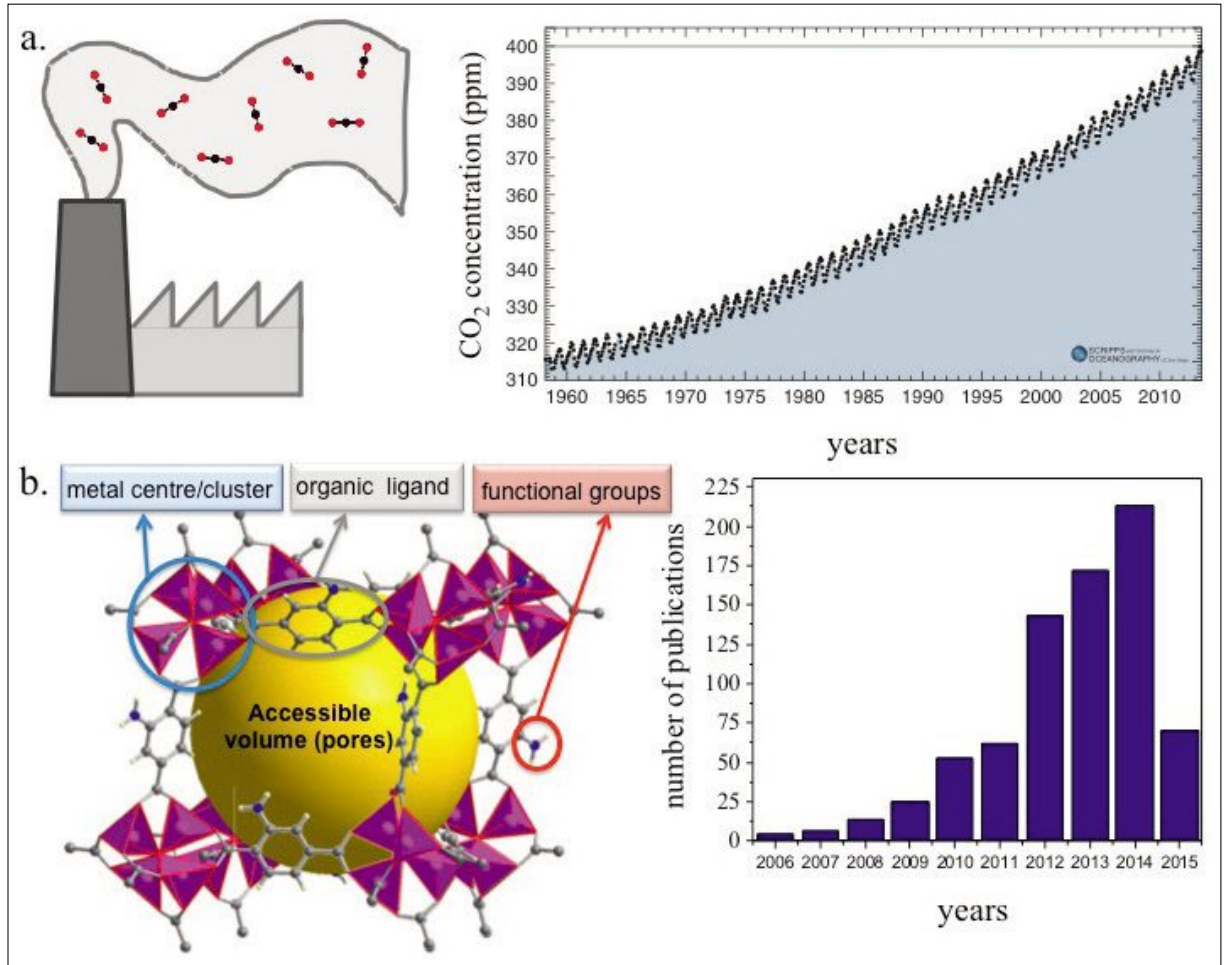

Fig. 1. a) Atmospheric $\mathrm{CO}_{2}$ concentration (mainly produced from large, stationary sources such as coal-fired power plants) during 1958-2013 (at Mauna Loa Observatory), showing the continuing and accelerating increase of $\mathrm{CO}_{2}$ in atmosphere, b) The strategic design of MOFs leads in the generation of materials with functionalized pores readily available for the selective capture of $\mathrm{CO}_{2}$. The number of publications (data obtained from ISI Web of Knowledge, Thomson Reuters on $30^{\text {th }}$ of March 2015) on ' $\mathrm{CO}_{2}$ capture and MOFs' per year, shows the increasing research interest in this topic.

rous activated carbons show both low $\mathrm{CO}_{2}$ adsorption capacities and low selectivities for $\mathrm{CO}_{2}$ over $\mathrm{N}_{2}$ in pressure regimes of interest for post-combustion capture.

Among several classes of porous materials, metal-organic frameworks (MOFs, Fig. 1b) provide an attractive means for the selective capture and utilization of $\mathrm{CO}_{2}$. A MOF is an infinite network of metal-ions or metal-ion clusters bridged by organic ligands through coordination bonds into a porous extended structure. Through the judicious selection of metal ion and ligand, which control pore size/shape and MOF-adsorbate interactions, uptake capacity and selectivity can be tuned. This inherent structural versatility has led to the discovery of a broad array of highly porous MOF materials with various topologies, compositions, and properties, such as record-breaking internal surface areas (up to $7000 \mathrm{~m}^{2} / \mathrm{g}$ ), ${ }^{[11]}$ high void volumes (up to $90 \%$ ) and low densities (down to $\left.0.19 \mathrm{~g} / \mathrm{cm}^{3}\right) .{ }^{[12]}$ The ability to chemically modify the materials through pre- or postsynthetic introduction of desired functional groups, combined with the potential for the formation of open-metal coordination sites can also provide the means to tailor internal surfaces for applications related to gas separations and storage, catalysis, and sensing. ${ }^{[13]}$ Towards the goal of improv- ing the efficiency of separation processes such as post-combustion capture, MOFs offer an unprecedented opportunity to target new materials with tunable interactions for the energy-efficient capture of $\mathrm{CO}_{2} \cdot{ }^{[14]}$ There are several excellent reviews show$\mathrm{CO}_{2}$ capture technologies. ${ }^{[6,14 a]}$ However, for their eventual implementation into post-combustion $\mathrm{CO}_{2}$ capture, MOFs must fulfill several crucial criteria:

a) MOFs should be easily synthesized in high yields, at low cost and over short periods of time.

b) MOFs must be produced on the nanoscale and exhibit good mechanical properties for crystals to be densely packed in pellets to maximize their volumetric capacity.

c) MOFs must maintain high adsorption capacity and selectivity for $\mathrm{CO}_{2}$ under application relevant conditions (i.e. at 0.15 bar and $40{ }^{\circ} \mathrm{C}$ and in the presence of other flue gas impurities such as $\mathrm{N}_{2}, \mathrm{NO}, \mathrm{SO}_{\mathrm{x}}$ and $\mathrm{H}_{2} \mathrm{O}$ ).

d) MOFs must be thermally and chemically stable upon activation (solvent removal), adsorption, and regeneration over thousands of cycles.

e) MOFs should require minimal energy input for the subsequent release of $\mathrm{CO}_{2}$ for materials regeneration. ing the great potential of MOFs in various
In this review we summarize developments in the MOF field concerning many of the aforementioned criteria that are necessary for their future implementation in post-combustion carbon capture technologies. It should be noted that much of the work related to MOFs and post-combustion capture is still in its infancy. For such a large-scale application it can be assumed that materials would need to be scaled up and their properties assessed not only in a laboratory type setting, but also in several stages in pilot test plants before being implemented into commercial capture processes.

\section{MOF Synthesis and Scale-up}

In a typical MOF synthesis a metal salt and ligand are dissolved in a solvent or solvent mixture and then heated at various temperatures and over varying periods of time (under solvo- or hydrothermal conditions). Although, the usage of these synthetic techniques can yield high quality crystals for structure determination and small-scale characterization, it often suffers from long reaction times and low product yield (milligram scale) that is difficult to scale up. ${ }^{[15]}$ For any large-scale energy related applications, especially for the capture of $\mathrm{CO}_{2}$ from power plants, porous adsorbents must be made with cheap, abundant, and nonhazardous metal salts and commercially available or easily synthesized ligands. ${ }^{[2]}$ Ideally, the framework syntheses must also be carried out with nontoxic solvents, over short periods of time, and in high yields, all while maintaining optimal adsorption properties. ${ }^{[6]}$ One difficulty related to scale-up synthesis is that MOF crystals nucleate at the surface of the vial, making the size of the reaction vessel a significant parameter in the synthesis conditions. Consequently, to date, MOF scaleup synthesis is limited to a few, commercially available iconic frameworks, such as HKUST-1 or Basolite C300 ( $\left[\mathrm{Cu}_{3}(1,3,5-\right.$ benzenetricarboxylate) $\left.\left.{ }_{2}\right]\right), \quad$ MIL-53 or Basolite A100 ([Al $(\mathrm{OH})(1,4-b e n z e n e d i-$ carboxylate)]), ZIF-8 or Basolite Z12OO ([Zn(2-methylimidazole) $\left.\left.)_{2}\right]\right)^{[16]}$ An additional challenge is that the scale-up synthesis of MOFs requires huge quantities of solvents, such as the diethylformamide (DEF) used in the synthesis of IRMOF-1 ([ $\left.\mathrm{Zn}_{4} \mathrm{O}(1,4 \text {-benzenedicarboxylate) })_{3}\right]$, also referred as MOF-5), that are quite expensive and difficult to regenerate. ${ }^{[17]}$ Thus, scale-up methods that decrease reaction times and cost are highly desirable for the isolation of MOFs that can be directly used and tested in large-scale capture of $\mathrm{CO}_{2}$ from power plants.

Several reaction conditions and methodologies have been employed to scale-up 
the synthesis of MOFs including the development of room temperature syntheses, microwave heating, ${ }^{[18]}$ the neat grinding of the reactants (mechanochemistry), ${ }^{[19]}$ continuous flow chemistry, ${ }^{[20]}$ and spray-drying. ${ }^{[21]}$ The ambient temperature synthesis is an attractive way to reduce energy consumption and hence cost associated with MOF formation. The simple mixing of several metal salts and ligands in a solvent mixture (DMF, DEF, ethanol and/or $\mathrm{H}_{2} \mathrm{O}$ ) at room temperature resulted in the isolation of pure phase IRMOF-0 (3D network with formula of $\left[\mathrm{Zn}_{4} \mathrm{O}\right.$ (acetylenedicarboxylic acid) ${ }_{3}$, IRMOF-1, M-MOF-74 (network with formula of $\left[\mathrm{M}_{2}\right.$ (2,5-dihydroxy1,4-benzenedicarboxylate)] where $\mathrm{M}$ $=\mathrm{Zn}(\mathrm{II}))$ and MOF-177 $\left(\left[\mathrm{Zn}_{4} \mathrm{O}(1,3,5-\right.\right.$ tris(4-carboxyphenyl)benzene) ${ }_{2}$ ]). [22] Interestingly, all these MOFs retained their $\mathrm{CO}_{2}$ uptake capacities compared with those made under solvothermal conditions.

The synthesis of MOFs in pure $\mathrm{H}_{2} \mathrm{O}$ represents a cheap way to synthesize MOFs in high yields, however, in most cases organic solvents such as dimethylformamide or alcohols must be employed in the synthesis in order to partially or fully dissolve polyaromatic ligands and isolate porous MOFs.

Microwave heating accelerates the rate of chemical reactions, achieved through rapid heating in microwave-absorbing solvents. ${ }^{[18 a]}$ Several MOFs have been synthesized with microwave heating such as the IRMOF family (3D networks with general formula of $\left.\left[\mathrm{Zn}_{4} \mathrm{O} \text { (dicarboxylate }\right)_{3}\right]$ ) and the reaction time was significantly reduced relative to the polycrystalline materials obtained from traditional solvothermal synthesis. ${ }^{[18 b]}$ While the microwave method decreases the time for the MOF synthesis, it still relies on the usage of solvents, whereas mechanochemical synthesis is a solvent-free methodology. Neat mixtures of the reactants - metal salt and ligand, are ground together in a ball mill to produce the desired MOF. Several MOFs have been synthesized using mechanochemistry including the porous $\mathrm{Cu}$ (ina) ${ }_{2}$ (after grinding copper(II) acetate and isonicotinic acid ina, for $10-15$ mins $)^{[19 b]}$ and azine-based MOFs. ${ }^{[19 c]}$ The latter study demonstrated that the size and shape of azine functionalized pores is a key factor for the capture of $\mathrm{CO}_{2}$, and since these frameworks can be obtained within only 15 min via mechanosynthesis, they could potentially be used for industrial studies on $\mathrm{CO}_{2}$ capture. While mechanochemical synthesis shows promise, it requires further investigation as traces of the reactants or amorphous byproducts are present with the MOFs and also to explore the generation of large pore based MOFs in high yields.

Two additional methodologies such as continuous flow chemistry and spray drying have been very recently employed in the scale-up synthesis of MOFs. A recent report revealed the synthesis of three iconic MOFs, HKUST-1, UiO-66 $\left(\mathrm{Zr}_{6} \mathrm{O}_{4}(\mathrm{OH})_{4}(1,4 \text {-benzene dicarboxylate })_{6}\right)$ and NOTT-400 ([Sc $\left.\mathrm{S}_{2} \mathrm{OH}\right)_{2}$ (biphenyl3,3',5,5'-tetracarboxylate)]) carried out with simultaneous pumping of reactant solutions into a T-micro mixer via HPLC pumps using a commercially available flow chemistry synthesis platform. ${ }^{[20 b]}$ The optimization of their synthesis conditions has led to unprecedented production efficiency, and control of their particle size without a loss of surface area or yield. The continuous flow production of these MOFs was expanded to a macro-scale reactor and the production rates were found to be from 2 to $60 \mathrm{~g} / \mathrm{h}$. The spray-drying methodology has been also used for the synthesis of MOFs and it enables the atomization of the MOF precursor solutions (metal salt and ligand solubilized in a solvent mixture) into aerosol droplets that are used as individual reactors for MOF synthesis.[21a] Then the droplets suspended in a hot-air stream start to evaporate, and the reactants diffuse to the droplet shell, where their concentration increases until reaching a critical level, at which point the MOF crystallizes. During the crystallization the mobility of the MOF crystals is reduced and therefore, they become closely packed within the droplet shell. Several MOFs including HKUST-1, ZIF-8, UiO-66, MIL-88A $\left(\left[\mathrm{Fe}_{3} \mathrm{O}\left(\mathrm{CH}_{3} \mathrm{OH}\right)_{3}(1,4-\right.\right.$ benzene dicarboxylate) $\left.)_{3}\right]$ ) and M-MOF-74 (where M: Zn(II), $\mathrm{Mg}(\mathrm{II})$ and $\mathrm{Ni}(\mathrm{II})$ ) were synthesized. HKUST-1 is prepared using the spray drying technique at a rate of $0.140 \mathrm{~g} / \mathrm{min}(\sim 8.4$ $\mathrm{g} / \mathrm{h}$ ) with yields up to $85 \%$. Also, since pure MOF crystals can be directly isolated without further filtration or purification and in a short period of time, spray drying is becoming a very attractive methodology to synthesize MOFs in large scale.

Once large scale, phase pure MOF syntheses are confirmed by powder X-ray diffraction, their $\mathrm{CO}_{2}$ adsorption capacity and selectivity over other flue gas impurities can be assessed.

\section{Assessment of $\mathrm{CO}_{2}$ Adsorption in MOFs}

For initial assessment of materials properties related to post-combustion $\mathrm{CO}_{2}$ capture, single component $\mathrm{CO}_{2}$ and $\mathrm{N}_{2}$ isotherms are typically collected at low pressures (up to 1 bar) and at variable temperatures ranging from $293 \mathrm{~K}$ to $313 \mathrm{~K}$. ${ }^{6]}$ These isotherms are first fit with high order polynomials such as a single or dual site Langmuir expression and then isosteric heats are subsequently extracted using the Clausius-Clapeyron or virial type equa- tions. ${ }^{[6 b]}$ The isosteric heat of adsorption, $\mathrm{Q}_{s t}$, is an important parameter that is defined as the average enthalpy of adsorption at constant coverage. The magnitude of this parameter dictates a materials affinity for $\mathrm{CO}_{2}$ and in turn, effects the selectivity of $\mathrm{CO}_{2}$ over other components in the flue gas stream and the amount of energy required to release $\mathrm{CO}_{2}$ during regeneration. Robust and porous MOFs most often exhibit type-I isotherms that are characteristic of microporous ( $<2 \mathrm{~nm}$ pore diameter) materials, however, depending on the ligands used and/or coordination around the metal ions, MOFs can be mesoporous ( $>2 \mathrm{~nm}$ pore diameter) or flexible and thus exhibit isotherms that have type-IV or sigmoidal shapes, respectively.

Maximizing the adsorption capacity and selectivity for $\mathrm{CO}_{2}$ (at low pressures) over other components in the flue gas stream is of paramount importance. At low pressures, the adsorption capacity is related to the strength and density of strong binding sites on the internal surface of the framework. On the other hand, given the similarities in the kinetic diameter of $\mathrm{CO}_{2}$ and $\mathrm{N}_{2}, 3.3$ and $3.6 \AA$, respectively, framework selectivity or separation ability is (thermodynamic in nature) based on the nature of the adsorptive interactions of the guest molecules with the framework surface. ${ }^{[23]}$ For physisorptive type interactions, the separation process relies on guest molecules having small disparities in their physical properties such as polarizability and quadrupole or dipole moments. For $\mathrm{N}_{2}$ and $\mathrm{CO}_{2}$ the largest defining difference is the larger quadrupole moment of $\mathrm{CO}_{2}$ over $\mathrm{N}_{2}, 13.4 \times 10^{-40} \mathrm{C} \cdot \mathrm{m}^{2}$ and $4.7 \times 10^{-40} \mathrm{C} \cdot \mathrm{m}^{2}$, respectively. ${ }^{[23]}$ As such, the introduction of structural components that exhibit highcharge densities on the framework surface, such as exposed metal cations, can be used to manipulate the selectivity. ${ }^{[14 b, 24]}$ As an alternative, chemisorptive interactions can also be used to dominate the separation ability of solid adsorbents. It is known that the carbon atoms in $\mathrm{CO}_{2}$ are highly susceptible to attack by nucleophiles. As a result strong Lewis bases, such as surface appended amines, ${ }^{[6]}$ can promote strong selectivity of $\mathrm{CO}_{2}$ over $\mathrm{N}_{2}$.

There are several relatively simple methods to assess a material's selectivity. The first is through the calculation of a selectivity factor (S) obtained from single-component isotherms. ${ }^{[25]}$ The selectivity factor is defined as the molar ratio of the adsorbed gases, $\mathrm{CO}_{2} / \mathrm{N}_{2}$, at pressures relevant to post-combustion carbon capture, $0.15 \mathrm{bar} / 0.75$ bar. Second, the Ideal Adsorbed Solution Theory (IAST), developed by Myers and Prausnitz, is a method used to model the behavior of mixed gas adsorption in frameworks through a mathematical fitting of single component iso- 
therms. ${ }^{[26]}$ Last, breakthrough experiments can be carried out where multicomponent gas streams are flowed through materials and then the gas stream composition is analyzed on the backend typically using a combination of gas chromatography and mass spectrometry. ${ }^{[6 b]}$

\section{Strategies to Capture $\mathrm{CO}_{2}$ with MOFs}

Several strategies have been developed to increase the low pressure $\mathrm{CO}_{2}$ adsorption capacity and enhance the $\mathrm{CO}_{2}$ binding affinity in MOFs. These strategies include: a) the incorporation of open metal sites, b) introduction of Lewis basic amine and other functional groups within MOFs, c) post-synthetic functionalization of the pore surface of MOFs (Fig. 2).

\subsection{Presence of Open Metal Sites}

Since the discovery of the first MOF with open metal sites, MOF-2 (2D network with formula of [ $\mathrm{Zn}_{2}$ (1,4-benzene dicarboxylate) $\left.{ }_{2}\right]$ ), it has been found that these structural features can enhance the surface packing density of adsorbates, induce selectivity in the binding of small guest molecules, and provide a means for charge transfer between the framework and included guest. ${ }^{[31]}$ While many MOFs containing open metal sites have been discovered serendipitously, through the insertion of solvent molecules into a metal coordination sites during synthesis, there are a few methods that have been employed to facilitate their formation including the incorporation of metalloligands or syntheses where open metal site-containing metal clusters are used $a b$ initio. ${ }^{[32]}$ Regardless of the synthetic strategy, solvent molecules bound to the coordination sphere of the metal must first be liberated, typically using a combination of heat and vacuum, before their $\mathrm{CO}_{2}$ adsorption properties can be assessed.

To date, there have been several widely studied MOF families discovered that contain open metal sites. The first most widely studied material was HKUST-1 featuring a cubic structure constructed by copper paddlewheels linked by triangular 1,3,5-benzenetricarboxylate ligands. ${ }^{[33]}$ The activation of HKUST- 1 leads to a network with open $\mathrm{Cu}$ (II) sites that shows a strong preference for $\mathrm{CO}_{2}$ over $\mathrm{N}_{2}$ with a relatively high $\mathrm{Q}_{\mathrm{st}}$ of $-30 \mathrm{~kJ} / \mathrm{mol}$, at low coverage. This high initial isosteric heat was found to be the result of $\mathrm{CO}_{2}$ binding directly to the open metal site. In situ infrared spectroscopic experiments revealed that $\mathrm{CO}_{2}$ coordinates in an end-on fashion $\mathrm{Cu}^{2+} \ldots \mathrm{O}=\mathrm{C}=\mathrm{O}$.

The adsorption of $\mathrm{CO}_{2}$ within other MOFs with open metal sites such as
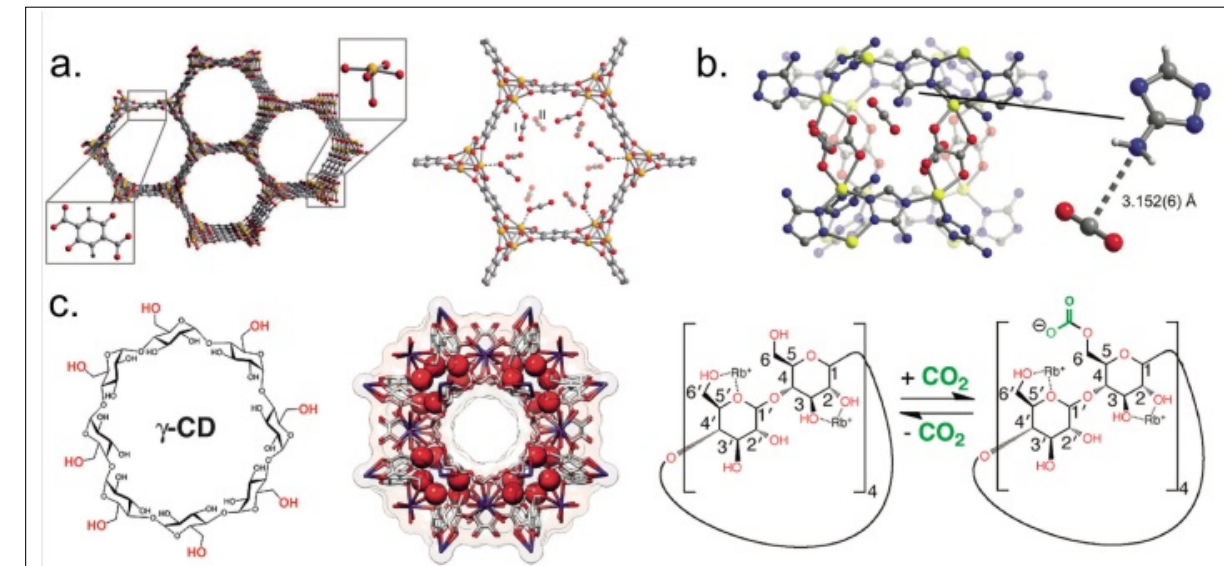

d.
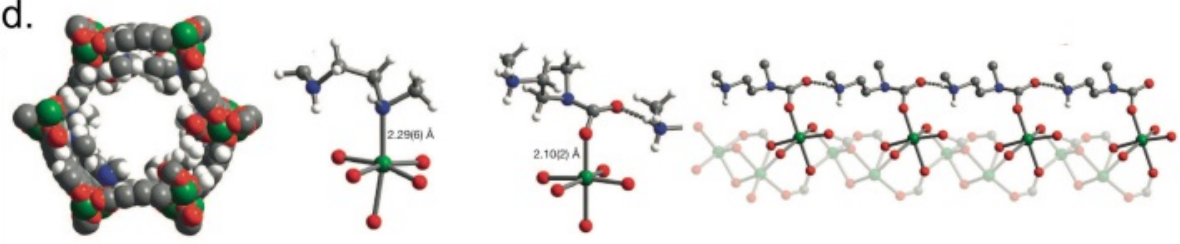

Fig. 2. Strategies to increase the low pressure $\mathrm{CO}_{2}$ adsorption capacity and enhance the $\mathrm{CO}_{2}$ binding affinity in MOFs: a. presence of open metal sites in M-MOF-74 (figure reproduced from ref. [27] with permission from the Royal Society of Chemistry), b. introduction of Lewis basic amine functionalities to form strong interactions with $\mathrm{CO}_{2}$ (figure reproduced from ref. [28] with permission from the AAAS), c) use of ligands with - $\mathrm{OH}$ functionalities in order to form carbonate species (figure reproduced from ref. [29] with permission from the American Chemical Society), and d) post-synthetic modification of the pores with alkyl-amines to promote the formation of a metal bond with $\mathrm{CO}_{2}$ (figure reproduced from ref. [30] with permission from the Nature Publishing Group).

the M-MIL-100 $\left(\left[\mathrm{M}_{3}(\mathrm{~F})\left(\mathrm{H}_{2} \mathrm{O}\right)_{2} \mathrm{O}(1,3,5-\right.\right.$ benzenetricarboxylate) ${ }_{2}$ ] where: $\mathrm{M}=$ Cr(III)) and M-MIL-101 (3D with formula of $\left[\mathrm{M}_{3} \mathrm{~F}\left(\mathrm{H}_{2} \mathrm{O}\right)_{2} \mathrm{O}(1,4\right.$-benzene dicarboxylate) ${ }_{3}$ ] where: $\mathrm{M}=\mathrm{Cr}(\mathrm{III})$ ) with surface areas of 1900 and $4230 \mathrm{~m}^{2} / \mathrm{g}$ respectively, led to high $\mathrm{Q}_{\mathrm{st}}$ of $\mathrm{CO}_{2}$ adsorption at zero-coverage of -62 and $-44 \mathrm{~kJ} / \mathrm{mol}$, respectively. ${ }^{[34]}$ This high binding enthalpy combined with stability upon activation at high temperatures, and in aqueous solutions, has sparked interest in these candidate frameworks for the post-combustion $\mathrm{CO}_{2}$ capture from flue gas. Other open metal sites of high charge such as $\mathrm{Al}^{3+}$ have also been found to be favorable for $\mathrm{CO}_{2}$ adsorption such as AlMIL-96 $\left(\mathrm{Al}_{12} \mathrm{O}(\mathrm{OH})_{18}\left(\mathrm{H}_{2} \mathrm{O}\right)_{3}\left(\mathrm{Al}_{2}(\mathrm{OH})_{4}\right)\right.$ (1,3,5-benzene tricarboxylate) $)_{6}$ which has a high $\mathrm{Q}_{\mathrm{st}}$ of $-33 \mathrm{~kJ} / \mathrm{mol}^{[35]}$ comparable to Al-MIL-53 and Cr-MIL-53 (-35 and -32 $\mathrm{kJ} / \mathrm{mol}$, respectively). ${ }^{[36]}$

To date, one of the best performing $\mathrm{CO}_{2}$ adsorbents in the low-pressure regime required for post-combustion capture is Mg-MOF-74. This MOF exhibits a honeycomb-like lattice with $1 \mathrm{D}$ channels that are lined with coordinatively unsaturated $\mathrm{Mg}^{2+}$ sites. The material exhibits a high $\mathrm{Q}_{s t}$ at low coverage, $-47 \mathrm{~kJ} / \mathrm{mol}^{\left[{ }^{[37]}\right.}$ The high $\mathrm{Q}_{s t}$, combined with the high density of open $\mathrm{Mg}^{2+}$ sites lends to the largest capacity of $\mathrm{CO}_{2}, \approx 26.1 \mathrm{wt} \%$, of any known material at 0.1 bar and $298 \mathrm{~K}$ (Fig. 3). Multiple in situ techniques, including neutron diffraction, infrared spectroscopy, NMR, and XAS have further supported that the exemplary adsorption properties are directly related to the presence of high densities of open $\mathrm{Mg}^{2+}$

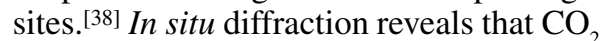
is bound to the metal in an end-on orientation that is angled with respect to the framework surface, a direct result of secondary van der Waals interactions between the $\mathrm{CO}_{2}$ and framework ligand. ${ }^{[27]}$ Further, chemical substitution of the metal cations leads to a number of isostructural analogs, where $\mathrm{M}^{2+}=\mathrm{Mg}, \mathrm{Mn}, \mathrm{Fe}, \mathrm{Co}, \mathrm{Ni}, \mathrm{Cu}$, or $\mathrm{Zn}$, and in turn allows significant tunability of the $\mathrm{CO}_{2}$ adsorption properties. To date, the M-MOF-74 series represents one of the most well-studied families of MOFs. The binding strength for $\mathrm{CO}_{2}$ has the following trend $(\mathrm{Cu}<\mathrm{Zn}<\mathrm{Mn}<\mathrm{Fe}<\mathrm{Co}<\mathrm{Ni})$ with adsorption capacity for $\mathrm{CO}_{2}$ at 0.1 bar and $298 \mathrm{~K}$ that range from 26.1 to $12.3 \mathrm{wt} \%$ from Mg-MOF-74 to Co-MOF-74, respectively. ${ }^{[39]}$ The observed isosteric heats do not follow the trend expected for the Irving Williams series or ionic radii and instead it was rationalized that the binding strength is dictated by nuclear screening affects of the $3 \mathrm{~d}$ electrons, dependent on the effective nuclear charge seen by the $\mathrm{CO}_{2}$ as it approaches the open metal coordination site.

Since the discovery of the MOF-74 structure type several groups have tried to alter the framework ligands, to tune the pore size. Yaghi et al. have demonstrated 


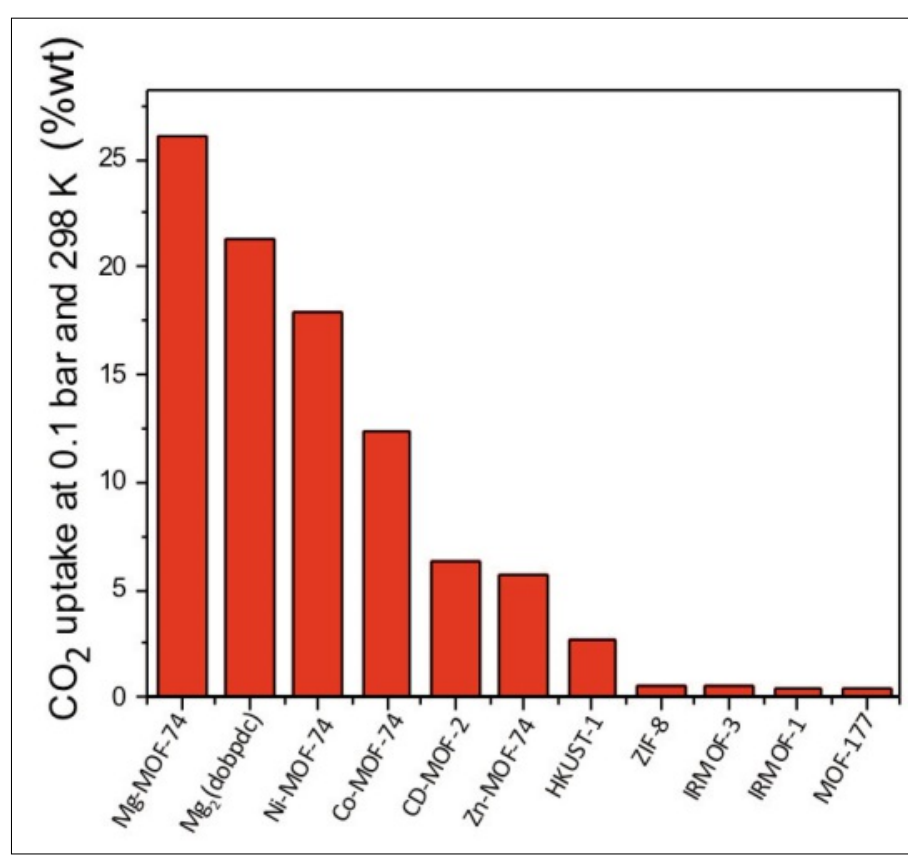

Fig. 3. Experimental $\mathrm{CO}_{2}$ uptake in several MOFs at 0.1 bar and $298 \mathrm{~K}$ (the data for Zn-MOF-74 and HKUST-1 were collected at slightly lower temperature at $294 \mathrm{~K}$ and $295 \mathrm{~K}$, respectively) (figure reproduced from ref. [39] with permission from the American Chemical Society). that pores as large as $98 \AA$ can be generated for a series of MOFs isoreticular to MOF-74 constructed by connecting their characteristic $1 \mathrm{D} \mathrm{Mg}$ (II) or $\mathrm{Zn}$ (II) oxide unit through sequentially longer organic linkers: from dihydroxy-terephthalate up to eleven phenyl rings.[12] $\mathrm{Mg}_{2}$ (dobpdc) (dobpdc $=4,4^{\prime}$-dioxido biphenyl-3,3'benzene dicarboxylate) is topologically identical to Mg-MOF-74 (or $\mathrm{Mg}_{2}$ (dobdc)) but features a ligand that is extended by one phenyl ring. [40] The material interacts strongly with $\mathrm{CO}_{2}$ as is reflected by the high $\mathrm{Q}_{s t}$ at low coverage of $-44 \mathrm{~kJ} / \mathrm{mol}$. This value is comparable to that observed for Mg-MOF-74 indicating an absence of pore size effects at low coverage and indicating the low coverage $\mathrm{Q}_{s t}$ value is entirely attributable to the interaction of $\mathrm{CO}_{2}$ with the unsaturated $\mathrm{Mg}^{2+}$ site.

\subsection{Introduction of Lewis Basic Amine and other Functional Groups}

An additional strategy to effectively capture $\mathrm{CO}_{2}$ within MOFs is the incorporation of Lewis basic groups (such as nitrogen-based groups, $-\mathrm{NH}_{2},-\mathrm{NH},-\mathrm{N}=\mathrm{N}$ ) within their structure. This can be achieved by utilizing ligands with such functionalities in the framework synthesis. Ideally, the interaction between the localized dipoles of $\mathrm{N}$-containing ligands and the quadrupole moment of $\mathrm{CO}_{2}$ can induce dispersion and electrostatic forces and therefore, form strong interactions between $\mathrm{CO}_{2}$ and the pore surface of MOFs.

The introduction of aromatic aminecontaining ligands is found to greatly improve their $\mathrm{CO}_{2}$ adsorption properties compared to those of their parent structures. As an example, the amine functionalized
IRMOF-3 adsorbs $0.4 \mathrm{wt} \%$ more $\mathrm{CO}_{2}$ compared to IRMOF-1, the non-functionalized analog, despite the decrease in the surface area - from 2833 to $2160 \mathrm{~m}^{2} / \mathrm{g}$. [41] Other MOFs where amine functionalization also leads to enhanced $\mathrm{CO}_{2}$ adsorption compared to their parent structure include the $\mathrm{NH}_{2}$-Al-MIL-53.[13a] and $\mathrm{NH}_{2}$-Uio-66. ${ }^{[42]}$ Rosi et al. have also observed that the decoration of the pore surface with the nitrogen-rich adenine ligand in bio-MOF-11 ([ $\mathrm{Co}_{2}$ (adeninate) $)_{2}$ (acetate) $\left.]\right)$ can introduce strong interactions with $\mathrm{CO}_{2}$ and the $\mathrm{Q}_{s t}$ is found to be $-45 \mathrm{~kJ} / \mathrm{mol} .{ }^{[43]}$ Finally, Shimizu et al. have for the first time observed the interactions occurring between $\mathrm{CO}_{2}$ and an amine-functionalized $\mathrm{MOF}, \mathrm{Zn}_{2}$ (Atz) (ox) (where Atz: 3-amino-1,2,4-Triazole and ox: oxalate) at low pressure using in situ single crystal X-ray diffraction experiments. ${ }^{29]} \mathrm{Zn}_{2}$ (Atz)(ox) has high $\mathrm{Q}_{\mathrm{st}}$ at low coverage, $-40.8 \mathrm{~kJ} / \mathrm{mol}$ and high selectivity for $\mathrm{CO}_{2}$ over $\mathrm{N}_{2}$ as $\mathrm{N}_{2}$ cannot diffuse within its pores. The $\mathrm{X}$-ray data revealed two independent $\mathrm{CO}_{2}$ binding sites within the pores of the MOF. One $\mathrm{CO}_{2}$ molecule is found near the free amine group and the second $\mathrm{CO}_{2}$ is close to the oxalates. The first adsorption site features hydrogen bonding with the free amine, $\mathrm{O}=\mathrm{C}=\mathrm{O} \cdots \mathrm{H}$ N-H (with a distance of $3.152 \AA$ ), and additional interactions between the lone pair of the $\mathrm{NH}_{2}$ group with the $\mathrm{C}$ atom of $\mathrm{CO}_{2}$. The experimental data were then combined with molecular simulations and it was concluded that the combination of appropriate pore size and shape, strong interactions between $\mathrm{CO}_{2}$ and amine functional groups on the pore surface, and intermolecular $\mathrm{CO}_{2}$ interactions are responsible for strong $\mathrm{CO}_{2}^{2}$ binding at low pressures.

Other functional groups such as nitro-, halogen- or hydroxyl- incorporated onto MOF ligands are also shown to improve $\mathrm{CO}_{2} / \mathrm{N}_{2}$ selectivity, $\mathrm{CO}_{2}$ heat of adsorption and/or low pressure $\mathrm{CO}_{2}$ uptake in MOFs compared to their parent MOF analogues. Some examples include:

a) Methyl-functionalization: The characterization of the methyl-functionalized $\mathrm{Zn}$ (bdc)(dmbpy) ${ }_{0.5}$ (where bdc: 1,4-benzene dicarboxylate and dmbpy: dimethyl 4,4'-bipyridyl) showed a decrease in surface area $\left(306 \mathrm{~m}^{2} / \mathrm{g}\right)$ and pore volume $\left(0.16 \mathrm{~cm}^{3} / \mathrm{g}\right)$ compared with the parent MOF, Zn(bdc)(bpy) ${ }_{0.5}$ (where bpy: 4,4'-bipyridyl) $\left(1070 \mathrm{~m}^{2} / \mathrm{g}\right.$ and $\left.0.44 \mathrm{~cm}^{3} / \mathrm{g}\right){ }^{[44]}$ Despite this, $\mathrm{Zn}(\mathrm{bdc})(\mathrm{dmbpy})_{0.5}$ uptakes $1.2 \mathrm{wt} \%$ more $\mathrm{CO}_{2}$ (at $298 \mathrm{~K}$ and 1 bar) than $\mathrm{Zn}$ (bdc)(bpy) ${ }_{0.5}$ and the methyl-functionalized MOF revealed a low coverage $\mathrm{Q}_{s t}$ of $-33.2 \mathrm{~kJ} / \mathrm{mol}$, a value that is higher than the $\mathrm{Q}_{s t}$ of the parent material $(-10 \mathrm{~kJ} /$ $\mathrm{mol})$. The stronger $\mathrm{CO}_{2} \cdots \mathrm{MOF}$ interaction is likely induced by the methyl group and the selectivity factor of $\mathrm{CO}_{2} / \mathrm{N}_{2}$ for $\mathrm{Zn}(\mathrm{bdc})$ $(\mathrm{dmbpy})_{0.5}$ extracted from single-component isotherm data was found to be 20.3, 34.8 and 39.8 at pressures of $0.2,0.6$ and 1.0 bar respectively.

b) Nitro- and halogen-functionalization: Banerjee et al. have studied how the pore size and functionality in isoreticular ZIFs affects the $\mathrm{CO}_{2}$ uptake and $\mathrm{CO}_{2} / \mathrm{N}_{2}$ selectivity. ${ }^{[45]}$ The $\mathrm{CO}_{2}$ uptake values at 1 bar and $298 \mathrm{~K}$ for several functionalized ZIFs analogues (networks with general formula of $[\mathrm{Zn}($ nitro-imidazolate $)(\mathrm{X})]$ where $\mathrm{X}$ is: i) nitro-benzene imidazolate for ZIF-78, ii) bromo-benzene imidazolate for ZIF-81, iii) chloro-benzene imidazolate for ZIF69 , iv) benzene imidazolate for ZIF-68 and v) methyl-benzene imidazolate for ZIF-79) varied quite significantly. Of the analogs studied, the $\mathrm{NO}_{2}$-functionalized material, ZIF-78, shows the largest $\mathrm{CO}_{2}$ uptake and breakthrough experiments reveal a high selectivity for $\mathrm{CO} / \mathrm{N}_{2}$ when introduced to binary mixtures. The $\mathrm{CO}_{2}$ uptake had the following trend: ZIF-78 > ZIF-81, ZIF-69 $>$ ZIF-68, ZIF-79. This behavior is easily rationalized since $\mathrm{CO}_{2}$ has a significant quadrupole moment and interacts stronger with more polar functional groups such as the $-\mathrm{NO}_{2}$

c) Hydroxyl-functionalization: The modification of $\mathrm{Zn}(\mathrm{bdc})(\mathrm{ted})_{05}$ with $\mathrm{OH}$ groups, $\mathrm{Zn}$ (bdc-OH)(ted) 0.5 (where bdc: 1,4-benzenedicarboxylate, bdc-OH: hydroxyl-1,4-benzenedicarboxylate and ted: triethylenediamine) led to an increased $\mathrm{CO}_{2}$ uptake despite slightly decreased surface area and pore volume.[46] Additionally, $\gamma$-cyclodextrin $(\gamma$-CD) molecules, which contain many -OH groups, have been utilized as ligands for the formation of several porous MOF structures that exhibit strong and selectively binding of $\mathrm{CO}_{2}$. A recent report by 
Stoddart et al. demonstrated the synthesis of CD-MOF-2 which is based on $\mathrm{Rb}(\mathrm{I})$ and the cyclic oligosaccharide $\gamma$-CD. [29] It is suggested that the strong affinity of CD-MOF-2 for $\mathrm{CO}_{2}$ at $273 \mathrm{~K}$ and low pressures is due to a chemisorptive process (when CD-MOF-2 uptakes $23 \mathrm{~cm}^{3} / \mathrm{g}$ ) in which the free hydroxyl-groups in $\mathrm{CD}$ MOF-2 react with $\mathrm{CO}_{2}$ molecules to form carbonic acid. The isotherms indicate that the binding of $\mathrm{CO}_{2}$ to the framework is reversible implying that the free alcohols can be regenerated. This was also supported with a color change of methyl red - from yellow (free - $\mathrm{OH}$ groups) to red (chemisorption of $\mathrm{CO}_{2}$ ) and back to yellow (desorption of $\mathrm{CO}_{2}$ and re-generation of free -OH groups).

\subsection{Post-synthetic Modification (PSM) of the Pore Surface of MOFs}

In addition to the aforementioned properties provided by open metal sites, such sites also afford an opportunity to post-synthetically append other small molecules to framework surfaces. PSM is an attractive means to further tune framework properties for various applications. Mimicking the chemistry observed for aqueous alkylamine-based scrubbers, recent work has focused on appending diamines to open metal sites in order to take advantage of the lower heat capacities of solid materials and hence lower regeneration energies. This strategy has been for the first time exploited by the post-synthetic functionalization of CuBTTri $\left(\mathrm{H}_{3}\left[\left(\mathrm{Cu}_{4} \mathrm{Cl}\right)_{3}(\mathrm{BTTri})_{8}\right.\right.$ where BTTri is 1,3,5-tri $(1 \mathrm{H}-1,2,3$-triazol-4-yl)benzene) with ethylenediamine (en) and $N, N^{\prime}$-dimethylethylenediamine (mmen). ${ }^{[47]}$ It is found that the properties of the secondary amine (mmen) functionalized CuBTTri compared to the properties of the framework functionalized with the primary amine (en) was much improved with regards to surface areas, 870 and $345 \mathrm{~m}^{2} / \mathrm{g}$, respectively, $\mathrm{Q}_{s t}$ of $\mathrm{CO}_{2},-96$ and $-78 \mathrm{~kJ} /$ mol, respectively, and $\mathrm{CO}_{2}$ uptake within the 0 to 1 bar pressure range. It should be noted that there were significant variations in the degree of post-synthetic amine appendage with 1 and 0.3 amines per $\mathrm{Cu}^{2+}$ in mmen-CuBTTri and en-CuBTTri, respectively. While not all of these properties are attributed to amine sterics, it is likely that steric hindrance around the secondary amines in mmen reduces hydrogen bonding between the molecules, allowing for a higher degree of post-synthetic modification and favoring better performance with regard to $\mathrm{CO}_{2}$ adsorption properties.

The introduction of alkylamines to open metal sites in MOFs is an attractive strategy to design $\mathrm{CO}_{2}$ adsorbents for a variety of applications related to sensing and scrubbing. These materials can be used for environments where $\mathrm{CO}_{2}$ is at very low concentrations $(\approx 400 \mathrm{ppm}$ in air) or there are varying levels of humidity. This has been highlighted by recent work that has reported the functionalization of $\mathrm{Mg}_{2}$ (dobpdc) with en and mmen, respectively. ${ }^{[40]}$ Relative to the parent material, their low pressure $\mathrm{CO}_{2}$ uptake and function in humid conditions were significantly improved. Further, McDonald et al. have shown that the low-pressure $\mathrm{CO}_{2}$ adsorption properties can be readily tuned via metal-substitution in mmen-M (dopbdc) where $\mathrm{M}=\mathrm{Mg}, \mathrm{Mn}, \mathrm{Fe}, \mathrm{Co}, \mathrm{Zn}^{\left[{ }^{20]}\right.}$ Mmen$\mathrm{M}_{2}$ (dopbdc) adsorbs $\mathrm{CO}_{2}$ by chemical insertion of the gas into the metal-ligand bonds of the framework and the strength of the metal-ligand bonds, and hence the ease of insertion and removal of the $\mathrm{CO}_{2}$, can be tuned systematically by varying the metal.

The post-synthetic modification of $\mathrm{Cr}$ $\mathrm{NH}_{2}$-MIL-101- using 'click chemistry' has resulted in the generation of a triazo-alkyl amine-MIL-101 with improved $\mathrm{CO}_{2}$ uptake at ambient pressure.[48] Interestingly, the $\mathrm{Q}_{s t}(-30 \mathrm{~kJ} / \mathrm{mol})$ was significantly lower than other alkylamine-functionalized materials likely indicating that $\mathrm{CO}_{2}$ is not directly interacting with the lone pair on the alkylamine to form a carbamate species. The improved $\mathrm{CO}_{2}$ uptake of the functionalized material could result from several phenomena such as a pore size effect where the amine molecules effectively lower the available pore volume increasing the number of van der Waals contacts between the $\mathrm{CO}_{2}$ and framework or a direct interaction between $\mathrm{CO}_{2}$ and the $\mathrm{N}$ atoms of the triazo link.

\section{Hydrolytic Stability of MOFs and Cyclability of Isotherms}

While many MOFs have desirable $\mathrm{CO}_{2}$ absorptive properties related to post-combustion capture, some are unstable in process conditions, making them unfeasible candidates. Trace chemicals in flue gas, such as water ( $5-7 \%$ by volume), can interfere with material performance through preferential adsorption or can break down the MOF pore structure via hydrolysis. ${ }^{[49]}$ Several synthetic approaches to improve hydrolytic stability and adsorption properties in the presence of water are currently underway. Many of these are related to improving hydrophobicity of frameworks through the incorporation of hydrophobic ligands or post-synthetically functionalizing the pore surface with hydrophobic molecules. To further minimize the likelihood of hydrolysis, other efforts are directed at creating frameworks with stronger coordination bonding interactions between metals and ligands as observed in the $\mathrm{Zr}$ (IV)based MOF, UiO-66. ${ }^{[50]}$
Many exceptional carboxylate-based MOFs that hold promise for the capture of $\mathrm{CO}_{2}$ such as IRMOF-1, MOF-177, MgMOF-74, and HKUST-1 are water labile. Recent studies on HKUST-1 revealed that water molecules attack and coordinate to the $\mathrm{Cu}$ (II) centers of the paddlewheel cluster, hydrolyzing the metal-ligand bonds and consequently displacing the organic ligands. ${ }^{[51]}$ This leads to the collapse of the 3D porous structure of HKUST-1 rendering a non-porous phase. In a recent study, the bulk powder of HKUST-1 was exposed to humidity under a variety of conditions and the extent of sample degradation was monitored by scanning electron microscopy and powder X-ray diffraction. ${ }^{[52]}$ It was found that the extent of degradation of HKUST-1 varied quite significantly when exposed to different levels of humidity, $40 \%$ or $90 \%$, at $40{ }^{\circ} \mathrm{C}$. The lower humidity level resulted in minimal degradation while the higher humidity level significantly increased the degradation process. In addition, the bulk material was found to degrade faster by slightly lowering the temperature to $25^{\circ} \mathrm{C}$. This is thought to be due to the water uptake capacity of HKUST-1, which under the conditions of $90 \%$ relative humidity is almost twice as much at $25{ }^{\circ} \mathrm{C}$ as at $40{ }^{\circ} \mathrm{C}$, allowing for the degradation to occur more rapidly. The degradation of Mg-MOF-74 crystals was also studied and it is found that its degradation is nearly complete after a day of exposure to any humid conditions.

The $\mathrm{CO}_{2}$ uptake capacities of M-MOF-74 (where $\mathrm{M}=\mathrm{Mg}, \mathrm{Ni}, \mathrm{Co}$, and $\mathrm{Zn}$ ) have been assessed after their exposure to $70 \%$ relative humidity. ${ }^{[53]}$ Significant decreases in the $\mathrm{CO}_{2}$ capacities were observed for $\mathrm{Mg}$ - and $\mathrm{Zn}$-MOF-74 with only $16 \%$ and $22 \%$ (at 0.15 bar) of their initial $\mathrm{CO}_{2}$ capacity, respectively. On the other hand, Ni- and Co-MOF-74 were more resistant to these conditions and their $\mathrm{CO}_{2}$ uptake corresponded to $61 \%$ and $85 \%$ of the initial capacities, respectively. The higher retention of $\mathrm{CO}_{2}$ with exposure to water is likely due to the different stabilities of these MOFs toward hydrolysis. While Mg-MOF-74 is currently the best performing MOF at ambient pressure and dry conditions, it cannot be used for the capture of $\mathrm{CO}_{2}$ under atmospheric conditions due to diminished adsorption properties in the presence of water. As such, it would require that water first be removed from flue gas streams, a process that is relatively energy intensive. Instead, several strategies have been developed to enhance the stability of MOFs in humid conditions including:

a) the incorporation of ligands functionalized with hydrophobic groups such as $-\mathrm{CH}_{3},-\mathrm{CF}_{3},-\mathrm{F}$ and phenyl groups, ${ }^{[54]}$ 
b) the incorporation of ligands based on hydrophobic cores such as the carborane core, ${ }^{[55]}$

c) encapsulation of hydrophobic guest molecules (e.g. fluorinated molecules, polyoxometalates, and carbon nanotubes) in their pores, ${ }^{[56]}$

d) functionalization of their surfaces via ligand replacement or with carbon coatings, [57] and

e) to coat the MOF crystals with hydrophobic organic polymers to produce MOF@ polymer composites. ${ }^{[58]}$

A recent report demonstrated that the encapsulation of HKUST-1 into polystyrene microspheres to form HKUST-1@ PS composites, improved the hydrolytic stability of HKUST-1 and most of the $\mathrm{CO}_{2}$ uptake capacity of HKUST-1 @PS was retained after their exposure at $80 \%$ relative humidity and $27^{\circ} \mathrm{C}$ up to 1 month (Fig. 4). ${ }^{[58]}$

While many carboxylate-based MOFs are hydrolytically unstable, there is a number of MOFs that possess high chemical and thermal stability. Some of the most well-known examples include those generated from either high-valent metal ions such as $\mathrm{Al}(\mathrm{III})$ (Al-MIL-110), $\mathrm{Cr}$ (III) (CrMIL-101) and Cr-MIL-100 and $\mathrm{Zr}(\mathrm{IV})$ (UiO-66) ${ }^{[50 a]}$ or various nitrogen-donor ligands containing imidazole (ZIFs), pyrazole, triazole, and tetrazole. Azolatebased ligands can bind metals with a similar geometry to carboxylate ligands, but their basicity results in the generation of stronger $\mathrm{M}-\mathrm{N}$ bonds and greater thermal and chemical stability in the resulting materials. It is expected that the higher the $\mathrm{pKa}$ of the ligand, the stronger the $\mathrm{M}-\mathrm{N}$ bond formed. The stability typically decreases with the pKa: pyrazole $(\mathrm{pKa}=14.4)$ ligands exhibit the greatest stability, imidazole $(\mathrm{pKa}=10.0)$ and triazole $(\mathrm{pKa}=9.3)$ are intermediate, and tetrazole $(\mathrm{pKa}=4.6)$ ligands are the most labile. ${ }^{[59]}$ The remarkable stability of some of these frameworks is illustrated by a pyrazole-based MOF, $\mathrm{Ni}_{3}$ (BTP) ${ }_{2}^{[60]}$ (where BTP is 1,3,5-benzene tris-pyrazolate) and ZIF-8 ${ }^{[61]}$ (an imidazolate network) which are stable in boiling water at $\mathrm{pH}$ 2-14 for at least 14 days.

The cyclability of $\mathrm{CO}_{2}$ isotherms on MOFs without damaging their $\mathrm{CO}_{2}$ uptake capacities is a key requirement for their utilization as carbon capture adsorbents in large power plants. A report by Suh et al. showed the cyclability of $\mathrm{CO}_{2}$ adsorption in SNU-100'-Ca (anionic MOF with formula of $\left[\mathrm{Zn}_{3}\right.$ (,4,6-tris-(4-carboxy-phenoxy)1,3,5-triazine $)_{2}$ (formate) $]^{-}\left[\mathrm{Ca}_{0.5}\right]^{+}$) which exhibited high zero-coverage $\mathrm{Q}_{s t}$ of -37.4 $\mathrm{kJ} / \mathrm{mol}$.62] The $\mathrm{CO}_{2}$ isotherms were measured for ten cycles at $298 \mathrm{~K}$ and 1 bar and revealed that there was no apparent decrease in the $\mathrm{CO}_{2}$ capacity and that the complete regeneration of the material oc-

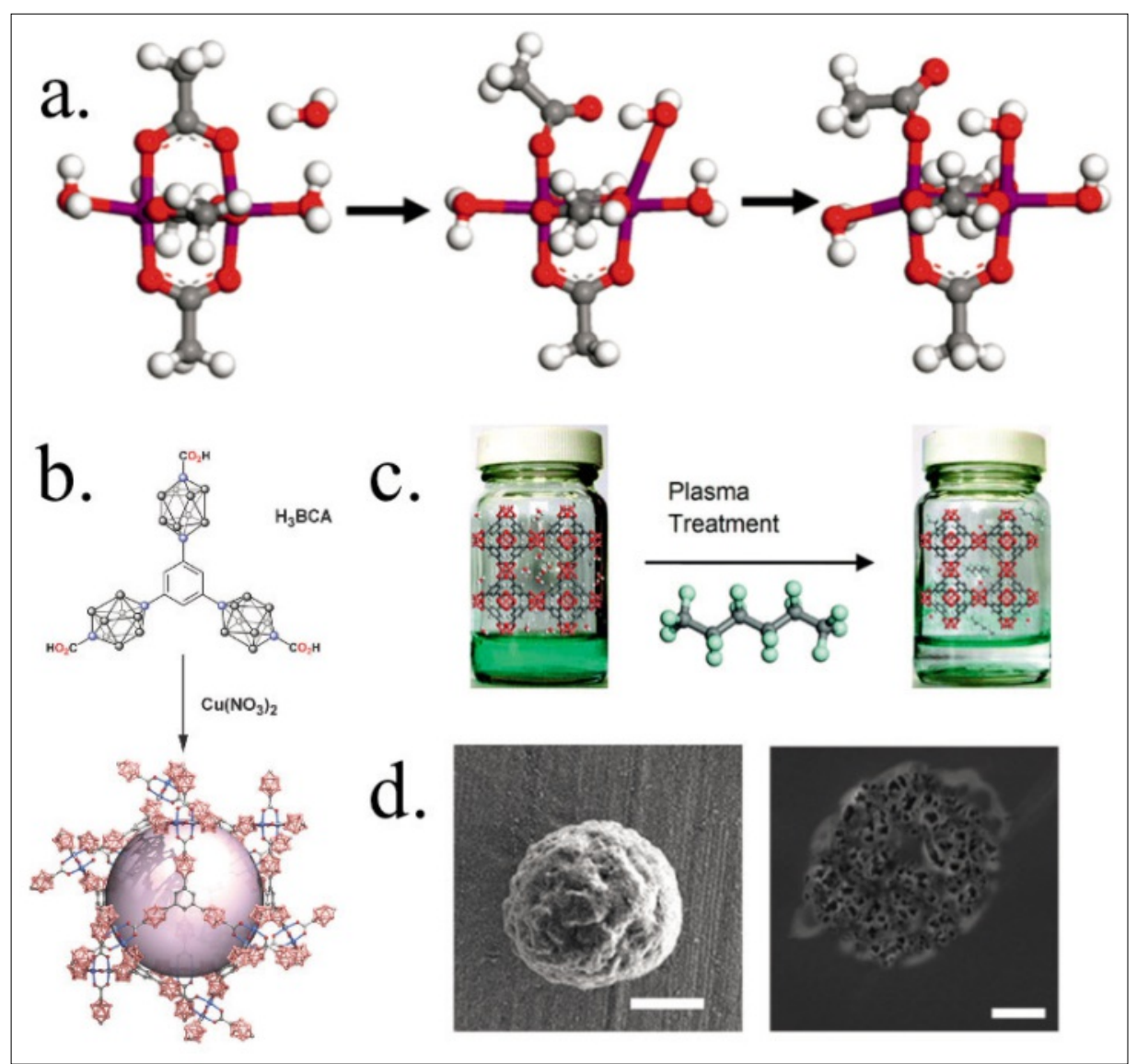

Fig. 4. a) Water molecules attack and coordinate to the $\mathrm{Cu}(\mathrm{II})$ centers of the paddlewheel cluster within HKUST-1, hydrolyzing the metal-ligand bonds and consequently displacing the organic ligands. This leads to a non-porous phase. ${ }^{[51]}$ Several strategies have been developed to improve the hydrolytic stability of MOFs including: b) the use of ligands with hydrophobic groups such as the carborane core (figure reproduced from ref. [55b] with permission from the Royal Society of Chemistry), c) the encapsulation of fluorinated molecules (figure reproduced from ref. [56a] with permission from the American Chemical Society), and d. generation of MOF based composites in which the MOF crystals are embedded within a polymeric matrix (figure reproduced from ref. [58] with permission from Wiley-VCH).

curred by evacuation without applying heat. An additional example by McDonald et al. showed that the $\mathrm{CO}_{2}$ capture performance of mmen- $\mathrm{Mg}_{2}$ (dobpdc) persists in the presence of water and the adsorptiondesorption cycles (tested over ten cycles with no uptake loss) can operate at elevated temperatures (70 and $100{ }^{\circ} \mathrm{C}$ ). This opens the door for many applications, as the temperature required for the post-combustion capture of $\mathrm{CO}_{2}$ is typically higher than ambient temperatures. ${ }^{[30]}$

\section{Mechanical Properties of MOFs}

The mechanical properties of MOFs are an aspect that has not been studied in detail compared to traditional polymers; however, recent progress has been made in correlating the changes in chemical structure with the observed characteristics. ${ }^{[63]}$ The dense packing of MOFs (or shaping MOFs into pellets; an important parameter for their use in power plants) without the loss of their structural characteristics is highly important as slight perturbations to the structural or chemical features could have a considerable effect on the overall performance of the capture system. In terms of the structural changes that have been observed to date, it has been demonstrated for HKUST-1 that the application of large pressures (on the order of several $\mathrm{GPa}$ ) can lower the total volume of the material by as much as $10 \%$. ${ }^{[64]}$ In addition, the effect of pressure on an IRMOF-1 single crystal from ambient pressure to 3.2GPa was explored. Initial compression to $0.8 \mathrm{GPa}$ represents a pressure region where solvent is 'squeezed' into the pores. The increase of pressure to $1.3 \mathrm{GPa}$ resulted in a decrease in volume and a marked decrease in solvent content as the solvent is evacuated from the pores. Further increase of pressure to $3.2 \mathrm{GPa}$ resulted in a gradual and steady reduction in volume and resolution of the data and above this pressure the sample becomes amorphous.[65]

It is not yet clear how this compression 
would affect the adsorption properties of a material (surface area, $\mathrm{CO}_{2}$ uptake capacity at low pressures) considering that they are still crystalline, but such effects would certainly worth investigating when evaluating MOFs within a real-world $\mathrm{CO}_{2}$ capture system.

\section{MOF Regeneration and $\mathrm{CO}_{2}$ Release}

As in the case of liquid amine scrubbers, the release of $\mathrm{CO}_{2}$ and the regeneration of MOF adsorbents employing pressure and/or temperature swing methods, could require significant energy input in instances where $\mathrm{CO}_{2}$ binds very strong. As such, the design of new solid adsorbent is primarily focused on finding a balance between the strong, selective binding of $\mathrm{CO}_{2}$ at temperatures up to $40^{\circ} \mathrm{C}$, and facile desorption processes, a property necessary to minimize regeneration energy.

In addition to the aforementioned balancing act, there are some clever methodologies that might be employed to also reduce regeneration energies. One such method involves the utilization of light to trigger framework dynamics that concomitantly causes $\mathrm{CO}_{2}$ release. A recent report described the synthesis of PCN-123 ([Zn ${ }_{4} \mathrm{O}\left(2\right.$-(phenyldiazenyl)terephthalate) $\left.{ }_{3}\right]$ which has the same topology as IRMOF-1) and is based on a photoactive azobenzenebearing ligand and $\mathrm{Zn}^{2+}$ (Fig. 5). ${ }^{66]}$ The azobenzene ligand could be transformed from trans-into the cis-conformation after UV light irradiation, resulting in an overall release of $53.9 \%$ of the originally adsorbed $\mathrm{CO}_{2}$ after $5 \mathrm{~h}$. PCN-123 could be easily regenerated by either standing at ambient conditions for a long period of time or by gentle heating at $60{ }^{\circ} \mathrm{C}$ for 20 hours. In addition to this example, $\mathrm{Zn}(\mathrm{AzDC})\left(4,4^{\prime}\right.$ $\mathrm{BPE})_{0.5}$ (where AzDC: azobenzene-4,4'dicarboxylate and 4,4'-BPE: trans-1,2bis(4-pyridyl)ethylene) reveals a strong and low-energy photoresponse leading to a dynamic and localized behavior, irrespective of the use of broadband or filtered light sources. ${ }^{[67]}$ It is shown that the bending about the azo-group occurs on a local scale in a dynamic fashion which is perfect for the regeneration of the MOF. This behavior was further studied to trigger and release $\mathrm{CO}_{2}$ and the exposure of $\mathrm{Zn}(\mathrm{AzDC})$ $\left(4,4^{\prime}-\mathrm{BPE}\right)_{0.5}$ to UV light resulted in releasing $\mathrm{CO}_{2}$ of up to $64 \%$ of the originally adsorbed $\mathrm{CO}_{2}$. Another attractive and feasible way to achieve $\mathrm{CO}_{2}$ desorption and regenerate MOFs is through heat and in this case the thermal conductivity of MOFs must be studied when they are densely packed in a bed system. To the best of our knowledge, IRMOF-1 is the only MOF on which thermal conductivity measurements were

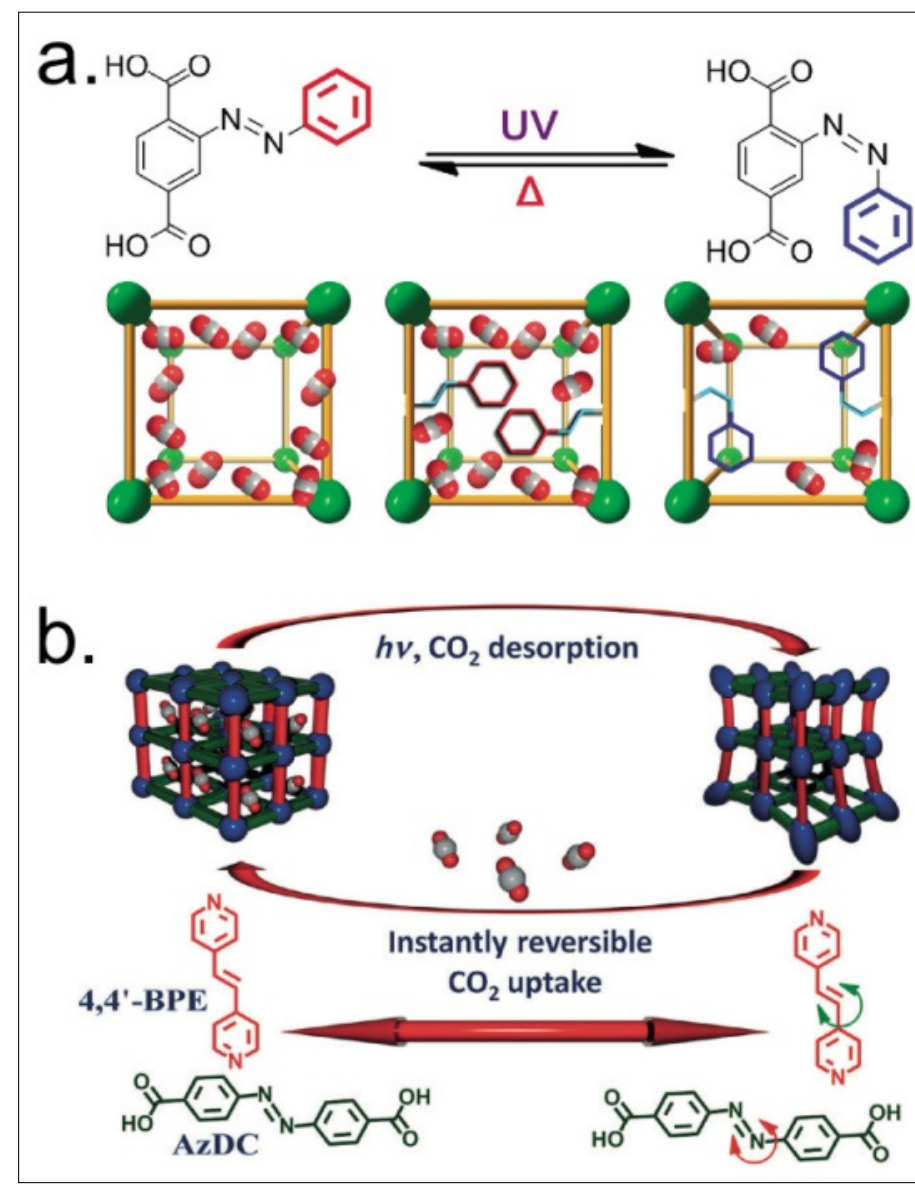

Fig. 5. a) Schematic illustration of the isomerization of the 2-(phenyldiazenyl) terephthalate ligand in $\mathrm{PCN}-123$ induced by UV irradiation, showing the suggested $\mathrm{CO}_{2}$ uptake in IRMOF-1, PCN-123trans, and PCN-123cis (figure reproduced from ref. [66] with permission from the American Chemical Society) and b) The dynamic photoswitching in the lightresponsive $\mathrm{Zn}(\mathrm{AzDC})$ $\left(4,4^{\prime}-\mathrm{BPE}\right)_{0.5}$ leads to instantly reversible $\mathrm{CO}_{2}$ uptake (figure reproduced from ref. [67] with permission from Wiley-VCH).

performed using the longitudinal, steadystate heat flow method, but the limited data prevented comparison either within MOFs or between MOFs and other types of $\mathrm{CO}_{2}$ adsorbents. ${ }^{[68]}$

\section{Summary and Outlook}

To summarize, MOFs are one of the most attractive classes of porous adsorbent materials currently available and this is due to their versatile architecture topologies, tunable pore sizes and functionalities, large surface areas, and amenability for post-synthetic modification. The high degree of control over their structural features offers us the opportunity to optimize framework properties, such as $\mathrm{CO}_{2}$ selectivity and capacity, control their functionality in varying flue gas compositions, all while minimizing the overall energy requirements for the capture process. These features clearly distinguish MOFs from other porous counterparts such as zeolites and activated carbons.

While we have presented several MOFs with demonstrated ability to selectively capture $\mathrm{CO}_{2}$ over $\mathrm{N}_{2}$, the main components in a flue gas stream, there are still a number of fundamental scientific problems to be addressed. There is a strong need to further understand how other smaller components in the flue gas effect a material's performance. To fill this knowledge gap, future experimental efforts should be focused on simulating actual working conditions for post-combustion carbon capture. Most of the $\mathrm{CO}_{2}$ adsorption studies reported are based on a single component (static gas) which is suitable for storage applications, but realistic assessment for the post-combustion gas separation of $\mathrm{CO}_{2} / \mathrm{N}_{2} / \mathrm{H}_{2} \mathrm{O}$ mixtures should require multicomponent adsorption measurements, since competitive adsorption is an important factor. ${ }^{[69]}$ Additionally, there is a need for more chemically and thermally stable materials whose structural integrity and adsorption properties can be maintained in the presence of water and when subjected to high temperatures necessary for regeneration. The best-known strategy to design more chemically and thermally robust materials is through the use of high-valence metal ions combined with strongly binding organic ligands. These efforts can be further aided by the development of materials with open metal-sites for the post-synthetic appendage of amines. The latter produces materials that are highly selective for $\mathrm{CO}_{2}$ and less likely to be affected by the presence of water relative to the parent materials. It should be noted that while it is not the focus of this review, the development of theoretical tools focused on the struc- 
ture and property prediction, are gaining maturity and are expected to begin providing insight into the engineering of porous media for solving specific problems such as carbon capture.

Once there are materials solutions to the more fundamental problems presented here, experimental efforts will naturally gain more focus beyond materials design. It is expected that further efforts will be made to address the scale-up of target frameworks, to assess MOF performance over many adsorption/desorption cycles, and to nanostructure materials for subsequent pelletizing processes. Further, it is expected that strong efforts will be made to assess the energy cost associated with the employment of specific MOFs into industrial capture processes. While the amine scrubbing solutions are responsible for a $\sim 30 \%$ energy penalty, to the best of our knowledge, there are no reports that precisely assess the energy cost associated with any MOF employment in CCS. We strongly believe that the enormous progress made during the last five years highlights the high potential of MOFs as carbon capture adsorbents, and this generates great expectations for their use in large pilot plants within the next 5 to 10 years.

Received: April 18, 2015

[1] Intergovernmental Panel on Climate Change Working Group I, Climate change 2013: the physical science basis: Working Group I contribution to the fifth assessment report of the Intergovernmental Panel on Climate Change, Eds. T. F. Stocker, D. Qin, G.-K. Plattner, M. Tignor, S.K. Allen, J. Boschung, A. Nauels, Y. Xia, V. Bex, P. M. Midgley, 2013.

[2] B. Smit, J. R. Reimer, C. M. Oldenburg, I. C. Bourg, 'Introduction to Carbon Capture and Sequestration', World Scientific, 2014

[3] a) R. Steeneveldt, B. Berger, T. A. Torp, Chem. Eng. Res. Des. 2006, 84, 739; b) 'IPCC Special Report on Carbon Dioxide Capture and Storage', Eds. B. Metz, O. Davidson, H. de Coninck, M. Loos, L. Meyer, Cambridge University Press, Cambridge, 2005, https:// www.ipcc.ch/pdf/special-reports/srccs/srccs wholereport.pdf.

[4] a) http://www.iea.org/; (b) S. M. Benson, in Workshop Proc. 'The 10-50 Solution: Technologies and Policies for a Low-Carbon Future', 2004.

[5] A. Demirbas, Progr. Ener. Combus. Sci. 2005, 31,171 .

[6] a) D. M. D'Alessandro, B. Smit, J. R. Long, Angew. Chem. Int. Ed. 2010, 49, 6058; b) K. Sumida, Z. R. Herm, T. McDonald, E. D. Bloch, J. Mason, H. J. Choi, J. R. Long, Chem. Rev. 2012, 112, 724.

[7] J. D. Figueroa, T. Fout, S. Plasynski, H. McIlvried, R. D. Srivastava, Int. J. Greenhouse Gas Control 2008, 2, 9.

[8] H. Bosch, G. F. Versteeg, W. P. M. Van Swaai, Chem. Eng. Sci. 1989, 44, 2735.

[9] a) K. T. Chue, J. N. Kim, Y. J. Yoo, S. H. Cho, R. T. Yang, Ind. Eng. Chem. Res. 1995, 34, 591; b) E. Díaz, E. Muñoz, A. Vega, S. Ordóñez, Ind. Eng. Chem. Res. 2008, 47, 412.

[10] J. Zhang, P. A. Webley, P. Xiao, Ener. Conver. Manag. 2008, 49, 346

[11] a) H. Furukawa, N. Ko, Y. B. Go, N. Aratani, S.
B. Choi, E. Choi, A. O. Yazaydin, R. Q. Snurr, M. O'Keeffe, J. Kim, O. M. Yaghi, Science 2010, 329, 424; b) O. K. Farha, I. Eryazici, N. C. Jeong, B. G. Hauser, C. E. Wilmer, A. A. Sarjeant, R. Q. Snurr, S. T. Nguyen, A. Ö. Yazaydın, J. T. Hupp, J. Am. Chem. Soc. 2012, 134, 15016.

[12] H. Deng, S. Grunder, K. E. Cordova, C. Valente, H. Furukawa, M. Hmadeh, F. Gándara, A. C. Whalley, Z. Liu, S. Asahina, H. Kazumori, M. O'Keeffe, O. Terasaki, J. F. Stoddart, O. M. Yaghi, Science 2012, 336, 1018.

[13] a) S. Couck, J. F. M. Denayer, G. V. Baron, T. Rémy, J. Gascon, F. Kapteijn, J. Am. Chem. Soc. 2009, 131, 6326; b) S. Keskin, D. S. Sholl, Ind. Eng. Chem. Res. 2008, 48, 914; c) S. Ma, H.-C. Zhou, Chem. Commun. 2010, 46, 44; d) L. Arnold, G. Averlant, S. Marx, M. Weickert, U. Müller, J. Mertel, C. Horch, M. Peksa, F. Stallmach, Chem. Ingen. Techn. 2013, 85, 1726; e) J.-R. Li, Y. Ma, M. C. McCarthy, J. Sculley, J. Yu, H.-K. Jeong, P. B. Balbuena, H.-C. Zhou, Coord. Chem. Rev. 2011, 255, 1791; f) X. Lin, N. R. Champness, M. Schröder, in 'Topics in Current Chemistry', Vol. 293, 2010, pp. 35-76; (g) J. Chun, S. Kang, N. Kang, S. M. Lee, H. J. Kim, S. U. Son, J. Mater. Chem. A 2013, 1, 5517.

[14] a) Y. Liu, Z. U. Wang, H.-C. Zhou, Greenhouse Gases: Sci. Technol. 2012, 2, 239; b) Z. Zhang, Y. Zhao, Q. Gong, Z Li, J. Li, Chem. Commun. 2013, 49, 653; c) P. Nugent, Y. Belmabkhout, S. D. Burd, A. J. Cairns, R. Luebke, K. Forrest, T. Pham, S. Ma, B. Space, L. Wojtas, M. Eddaoudi, M. J. Zaworotko, Nature 2013, 495, 80; (d) B. K. Chang, P. D. Bristowe, A. K. Cheetham, Phys. Chem. Chem. Phys. 2013, 15, 176; (e) N. H. Alsmail, M. Suyetin, Y. Yan, R. Cabot, C. P. Krap, J. Lü, T. L. Easun, E. Bichoutskaia, W. Lewis, A. J. Blake, M. Schröder, Chem. Eur. J. 2014, 20, 7317; f) S. Yang, X. Lin, W. Lewis, M. Suyetin, E. Bichoutskaia, J. E. Parker, C. C. Tang, D. R. Allan, P. J. Rizkallah, P. Hubberstey, N. R. Champness, K. Mark Thomas, A. J. Blake, M. Schröder, Nat. Mater. 2012, 11, 710.

[15] S. T. Meek, J. A. Greathouse, M. D. Allendorf, Adv. Mater. 2011, 23, 249.

[16] http://www.sigmaaldrich.com/materialsscience/alternative-energy-materials/metalorganic-frameworks. html.

[17] U. Mueller, M. Schubert, F. Teich, H. Puetter, K. Schierle-Arndt, J. Pastre, J. Mater. Chem. 2006, 16, 626 .

[18] a) J. Klinowski, F. A. Almeida Paz, P. Silva, J. Rocha, Dalton Trans. 2011, 40, 321; b) Y.-K. Seo, G. Hundal, I. T. Jang, Y. K. Hwang, C.H. Jun, J.-S. Chang, Microporous Mesoporous Mater. 2009, 119, 331.

[19] a) T. Friščić, in 'Encyclopedia of Inorganic and Bioinorganic Chemistry', John Wiley \& Sons, Ltd, 2011; b) A. Stolle, 'Ball Milling Towards Green Synthesis: Applications, Projects, Challenges', Royal Society of Chemistry, 2014; (c) M. Y. Masoomi, K. C. Stylianou, A. Morsali, P. Retailleau, D. Maspoch, Cryst. Growth Des. 2014, 14, 2092.

[20] a) P. A. Bayliss, I. A. Ibarra, E. Perez, S. Yang, C. C. Tang, M. Poliakoff, M. Schroder, Green Chem. 2014, 16, 3796; b) M. Rubio-Martinez, M. P. Batten, A. Polyzos, K.-C. Carey, J. I. Mardel, K.-S. Lim, M. R. Hill, Sci. Rep. 2014, $4,5443$.

[21] a) A. Carné-Sànchez, I. Imaz, M. Cano-Sarabia, D. Maspoch, Nat. Chem. 2013, 5, 203; b) A. Garcia Marquez, P. Horcajada, D. Grosso, G. Férey, C. Serre, C. Sanchez, C. Boissiere, Chem. Commun. 2013, 49, 3848.

[22] D. J. Tranchemontagne, J. R. Hunt, O. M. Yaghi, Tetrahedron 2008, 64, 8553.

[23] S. Sircar, Ind. Eng. Chem. Res. 2006, 45, 5435.

[24] A. Das, D. M. D'Alessandro, CrystEngComm 2014, 16, 9158.
[25] J.-R. Li, R. J. Kuppler, H.-C. Zhou, Chem. Soc. Rev. 2009, 38, 1477.

[26] a) A. L. Myers, J. M. Prausnitz, AIChE 1965, 11, 121; b) H. O. R. Landa, D. Flockerzi, A. Seidel-Morgenstern, AIChE 2013, 59, 1263.

[27] W. L. Queen, M. R. Hudson, E. D. Bloch, J. A. Mason, M. I. Gonzalez, J. S. Lee, D. Gygi, J. D. Howe, K. Lee, T. A. Darwish, M. James, V. K. Peterson, S. J. Teat, B. Smit, J. B. Neaton, J. R. Long, C. M. Brown, Chem. Sci. 2014, 5, 4569.

[28] R. Vaidhyanathan, S. S. Iremonger, G. K. H. Shimizu, P. G. Boyd, S. Alavi, T. K. Woo, Science 2010, 330, 650

[29] J. J. Gassensmith, H. Furukawa, R. A Smaldone, R. S. Forgan, Y. Y. Botros, O. M. Yaghi, J. F. Stoddart, J. Am. Chem. Soc. 2011, $133,15312$.

[30] T. M. McDonald, J. A. Mason, X. Kong, E. D. Bloch, D. Gygi, A. Dani, V. Crocella, F. Giordanino, S. O. Odoh, W. S. Drisdell, B. Vlaisavljevich, A. L. Dzubak, R. Poloni, S. K. Schnell, N. Planas, K. Lee, T. Pascal, L. F. Wan, D. Prendergast, J. B. Neaton, B. Smit, J. B. Kortright, L. Gagliardi, S. Bordiga, J. A. Reimer, J. R. Long, Nature 2015, 519, 303.

[31] H. Li, M. Eddaoudi, T. L. Groy, O. M. Yaghi, J. Am. Chem. Soc. 1998, 120, 8571.

[32] D. Feng, W.-C. Chung, Z. Wei, Z.-Y. Gu, H.L. Jiang, Y.-P. Chen, D. J. Darensbourg, H.-C. Zhou, J. Am. Chem. Soc. 2013, 135, 17105.

[33] a) S. S.-Y. Chui, S. M.-F. Lo, J. P. H. Charmant, A. G. Orpen, I. D. Williams, Science 1999, 283, 1148 ; b) S. Bordiga, L. Regli, F. Bonino, E. Groppo, C. Lamberti, B. Xiao, P. S. Wheatley, R. E. Morris, A. Zecchina, Phys. Chem. Chem. Phys. 2007, 9, 2676; c) A. Vishnyakov, P. I. Ravikovitch, A. V. Neimark, M. Bülow, Q. M. Wang, Nano Lett. 2003, 3, 713.

[34] P. L. Llewellyn, S. Bourrelly, C. Serre, A. Vimont, M. Daturi, L. Hamon, G. De Weireld, J.-S. Chang, D.-Y. Hong, Y. Kyu Hwang, S. Hwa Jhung, G. Férey, Langmuir 2008, 24, 7245.

[35] T. Loiseau, L. Lecroq, C. Volkringer, J. r. m. Marrot, G. Férey, M. Haouas, F. Taulelle, S. Bourrelly, P. L. Llewellyn, M. Latroche, J. Am. Chem. Soc. 2006, 128, 10223.

[36] S. Bourrelly, P. L. Llewellyn, C. Serre, F. Millange, T. Loiseau, G. Férey, J. Am. Chem. Soc. 2005, 127, 13519.

[37] S. R. Caskey, A. G. Wong-Foy, A. J. Matzger, J. Am. Chem. Soc. 2008, 130, 10870 .

[38] X. Kong, E. Scott, W. Ding, J. A. Mason, J. R. Long, J. A. Reimer, J. Am. Chem. Soc. 2012, 134, 14341.

[39] A. Özgür Yazaydin, R. Q. Snurr, T.-H. Park, K. Koh, J. Liu, M. D. LeVan, A. I. Benin, P. Jakubczak, M. Lanuza, D. B. Galloway, J. J. Low, R. R. Willis, J. Am. Chem. Soc. 2009, 131, 18198.

[40] T. M. McDonald, W. R. Lee, J. A. Mason, B. M. Wiers, C. S. Hong, J. R. Long, J. Am. Chem. Soc. 2012, 134, 7056.

[41] A. R. Millward, O. M. Yaghi, J. Am. Chem. Soc. 2005, 127, 17998.

[42] Q. Yang, A. D. Wiersum, P. L. Llewellyn, V. Guillerm, C. Serre, G. Maurin, Chem. Commun. 2011, 47, 9603.

[43] J. An, S. J. Geib, N. L. Rosi, J. Am. Chem. Soc. 2010, 132, 38.

[44] H. Liu, Y. Zhao, Z. Zhang, N. Nijem, Y. J. Chabal, H. Zeng, J. Li, Adv. Funct. Mater. 2011, 21, 4754.

[45] R. Banerjee, H. Furukawa, D. Britt, C. Knobler, M. O'Keeffe, O. M. Yaghi, J. Am. Chem. Soc. 2009, 131, 3875 .

[46] Y. Zhao, H. Wu, T. J. Emge, Q. Gong, N. Nijem, Y. J. Chabal, L. Kong, D. C. Langreth, H. Liu, H. Zeng, J. Li, Chem. Eur. J. 2011, 17, 5101.

[47] a) A. Demessence, D. M. D'Alessandro, M. L. Foo, J. R. Long, J. Am. Chem. Soc. 2009, 131, 8784 ; b) T. M. McDonald, D. M. D’Alessandro, 
R. Krishna, J. R. Long, Chem. Sci. 2011, 2, 2022.

[48] P.-Z. Li, X.-J. Wang, R. H. D. Tan, Q. Zhang, R. Zou, Y. Zhao, RSC Adv. 2013, 3, 15566

[49] N. ul. Qadir, S. A. M. Said, H. M. Bahaidarah, Microporous Mesoporous Mater. 2015, 201, 61

[50] a) T. Devic, C. Serre, Chem. Soc. Rev. 2014, 43 6097; b) J. H. Cavka, S. r. Jakobsen, U. Olsbye, N. Guillou, C. Lamberti, S. Bordiga, K. P. Lillerud, J. Am. Chem. Soc. 2008, 130, 13850.

[51] G. Majano, O. Martin, M. Hammes, S. Smeets, C. Baerlocher, J. Pérez-Ramírez, Adv. Funct. Mater. 2014, 24, 3855.

[52] J. B. DeCoste, G. W. Peterson, B. J. Schindler, K. L. Killops, M. A. Browe, J. J. Mahle, J. Mater. Chem. A 2013, 1, 11922 .

[53] A. C. Kizzie, A. G. Wong-Foy, A. J. Matzger, Langmuir 2011, 27, 6368.

[54] a) T. Wu, L. Shen, M. Luebbers, C. Hu, Q Chen, Z. Ni, R. I. Masel, Chem. Commun. 2010, 46, 6120; b) H. Jasuja, Y.-g. Huang, K. S. Walton, Langmuir 2012, 28, 16874.

[55] a) Y.-S. Bae, O. K. Farha, A. M. Spokoyny, C. A. Mirkin, J. T. Hupp, R. Q. Snurr, Chem
Commun. 2008, 4135; b) D. J. Clingerman, W. Morris, J. E. Mondloch, R. D. Kennedy, A. A Sarjeant, C. Stern, J. T. Hupp, O. K. Farha, C. A. Mirkin, Chem. Commun. 2015, 51, 6521

[56] a) J. B. Decoste, G. W. Peterson, M. W. Smith, C. A. Stone, C. R. Willis, J. Am. Chem. Soc. 2012, 134, 1486; b) D. Mustafa, E. Breynaert, S. R. Bajpe, J. A. Martens, C. E. A. Kirschhock, Chem. Commun. 2011, 47, 8037; c) S. J. Yang, J. Y. Choi, H. K. Chae, J. H. Cho, K. S. Nahm, C. R. Park, Chem. Mater. 2009, 21, 1893.

[57] a) X. Liu, Y. Li, Y. Ban, Y. Peng, H. Jin, H. Bux, L. Xu, J. Caro, W. Yang, Chem. Commun. 2013 49, 9140; b) S. J. Yang, C. R. Park, Adv. Mater. 2012, 24, 4010.

[58] A. Carné-Sánchez, K. C. Stylianou, C. Carbonell, M. Naderi, I. Imaz, D. Maspoch, Adv. Mater. 2015, 27, 869.

[59] C. Ebert, J. Elguero, G. Musumarra, J. Phys. Org. Chem. 1990, 3, 651.

[60] V. Colombo, S. Galli, H. J. Choi, G. D. Han, A. Maspero, G. Palmisano, N. Masciocchi, J. R. Long, Chem. Sci. 2011, 2, 1311.

[61] K. S. Park, Z. Ni, A. P. Côté, Choi, R. Huang,
F. J. Uribe-Romo, H. K. Chae, M. O'Keeffe, O. M. Yaghi, Proc. Natl. Acad. Sci. USA 2006, 103, 10186.

[62] H. J. Park, M. P. Suh, Chem. Sci. 2013, 4, 685

[63] J. C. Tan, A. K. Cheetham, Chem. Soc. Rev. 2011, 40, 1059.

[64] K. W. Chapman, G. J. Halder, P. J. Chupas, J. Am. Chem. Soc. 2008, 130, 10524.

[65] A. J. Graham, D. R. Allan, A. Muszkiewicz, C. A. Morrison, S. A. Moggach, Angew. Chem. Int Ed. 2011, 50, 11138

[66] J. Park, D. Yuan, K. T. Pham, J.-R. Li, A. Yakovenko, H.-C. Zhou, J. Am. Chem. Soc. 2012, 134, 99.

[67] R. Lyndon, K. Konstas, B. P. Ladewig, P. D. Southon, P. C. J. Kepert, M. R. Hill, Angew. Chem. Int. Ed. 2013, 52, 3695.

[68] B. L. Huang, Z. Ni, A. Millward, A. J. H. McGaughey, C. Uher, M. Kaviany, O. Yaghi, Int. J. Heat Mass Transfer 2007, 50, 405.

[69] J. A. Mason, T. M. McDonald, T.-H. Bae, J. E. Bachman, K. Sumida, J. J. Dutton, S. S. Kaye, J. R. Long, J. Am. Chem. Soc. 2015, 137, 4787. 